\title{
CONFLICTO LINGÜÍSTICO Y SEPARATISMO EN CANADÁ*
}

\author{
Juan José Torres Núñez**
}

Resumen: Este artículo analiza la historia del conflicto lingüístico entre el pueblo francófono y el pueblo anglófono dentro de la doble realidad cultural de Canadá y muestra el imperialismo inglés hacia el pueblo québécois a lo largo de su historia. Con respecto a la posible independencia de Quebec, el artículo habla a favor de un Canadá unido sin miedo de ofender a los québécois. Y se desprenden dos conclusiones: una emocional y otra racional. La emocional nos recuerda las palabras del profesor Russell: "Amo a Canadá”, "Canadá es un gran país”. En la racional se nos recuerda las trágicas consecuencias de la desintegración de imperios y naciones. Y se afirma que los québécois no van a vivir mejor si se separan del resto de Canadá. Lo que se necesita verdaderamente es un federalismo más interactivo y más económicamente independiente de los Estados Unidos.

Palabras clave: Conflicto lingüístico, francófono, anglófono, federalismo, separatismo.

\begin{abstract}
This article examines the history of the linguistic conflict between Francophones and Anglophones within the double cultural reality of Canada and shows the English imperialism towards the Quebecois throughout their history. With regard to the possible independence of Quebec, the article discusses Canadian unity without fear of offending the Quebecois. Two conclusions stand out: one emotional and another rational. The emotional one reminds us of Professor Russell's words: "I love Canada", "Canada is a great place". The rational conclusion reminds us of the tragic consequences of the disintegration of empires and nations. It is asserted that the Quebecois will not live better if they separate from the rest of Canada. What the country really needs is a federalism, more interactive and more economically independent from the United States.

Key words: Linguistic conflict, Francophone, Anglophone, federalism, separatism.
\end{abstract}

Canadá es un país formado por la convivencia pacífica de varios pueblos y de varias culturas. Hay que distinguir en primer lugar, al pueblo autóctono, es decir, los aborígenes que vivían allí antes de la llegada de los franceses y de los ingleses. El pueblo francés y el pueblo inglés, descendientes de los colonos provenientes de Francia y de Inglaterra, constituyen la mayor parte de los habitantes que hoy pueblan Canadá. Ambas culturas han creado a lo largo de la historia lo que el novelista Hugh MacLenan llama Two Solitudes (Dos Soledades). Pero también existen otros grupos humanos ligados por una cultura

Fecha de recepción: abril 2005

Fecha de aceptación y versión final: febrero 2006

** Profesor titular, Departamento de Filología Inglesa y Alemana, Universidad de Almería; $\bowtie$ jotorres@ual.es.

Odisea, $\mathrm{n}^{\circ}$ 7, ISSN 1578-3820, 2006, 193-202 
distinta: suele denominárseles bajo apelativos diversos, tales como "mosaico cultural", "otros grupos étnicos", "multiculturalismo", "nuevos canadienses" o "tercera fuerza". Yo prefiero designarlos como "cuarto pueblo" y en él agrupo a los inmigrantes de distintos países que viven en Canadá y que juegan un papel muy importante en el desarrollo del país y, con su voto, en el proceso electoral. Este pueblo ha dado a Canadá gran número de artistas y de escritores. Tenemos nombres como Susan Musgrove (que nació en California), Robyn Sarah (de Nueva York), Mary di Michele y Pier Giorgio di Cicco (ambos de Italia), Michael Ondaatje (de Sri Lanka), por citar unos cuantos (véase Bernd Dietz, 1985). Hoy se estima que el $73 \%$ de los canadienses habla inglés, el $26 \%$ habla francés y el $7 \%$ habla otra lengua diferente en casa.

Este artículo analiza el conflicto lingüístico entre el pueblo francófono y el pueblo anglófono dentro de la doble realidad cultural de Canadá. Y ante el posible desmembramiento del país por la separación o la independencia del pueblo francés, Quebec, yo abogo por la comprensión, el respeto mutuo, la colaboración y la unión de Quebec con el resto de Canadá. Mel Hurtig nos recuerda que muchos canadienses sienten miedo al hablar de unión. "The fear of offending the Quebecois has been taken to the ridiculous extremes that far too many Canadians are now afraid to speak out strongly for national unity" (1992: 303). Pero veamos - de forma breve- la historia de la lengua francesa y de la lengua inglesa desde la conquista hasta nuestros días. Son datos archiconocidos pero que conviene recordar ahora.

En el año 1663 el rey de Francia, Luis XIV, decide organizar la colonia francesa en América del Norte, la Nouvelle France. Llegan expediciones gloriosas procedentes de la metrópolis. Y Talon anima a que se casen los hombres a partir de los 18 años y las mujeres a partir de los 14. Según Kenneth McNaught "the price of revived royal interest was the ending of the private fur-trade monopoly" (1969: 27). In 1663 New France, with a population of barely 2,000 , became a royal province complete with a replica of French provincial government and law."

Después del tratado de Utrecht, en 1714, Francia se desentiende de la colonia. Cuando en 1748 Luis XV firma el tratado de Aix-la-Chappelle y Louisbourg -en la isla del Cabo Breton- pasa a los franceses. Esto enfurece a los colonos de la Nouvelle Angleterre -la colonia inglesa en América del Norte. El resto de la Acadie, por su parte, queda en manos de los ingleses y esto enfurece a los colonos de la Nouvelle France. McNaught señala que "it was a hollow diplomatic victory which simply intensified English-American determination to be rid of the encircling line of French Catholic power" (1969: 38). Los administradores ingleses de la Acadie quieren que los Acadiens desaparezcan. Pero esto no sucederá si los franceses aceptan una asimilación. La guerra de la asimilación comienza. En 1755 los ingleses deportan a 7.000 Acadiens a las costas americanas de la Nouvelle Orleáns. Los ingleses continúan deportando franceses hasta cuatro años después de la Conquista en 1760 .

En 1750 la Nouvelle France estaba formada por un territorio que se extendía desde el valle de Sain-Laurent hasta el Golfo de México. Un espacio inmenso con sólo 80.000 habitantes. La Nouvelle Angleterre era veinte veces más pequeña y se encontraba encerrada entre el Atlántico y las montañas Apalaches. Su población, sin embargo, llegaba a 1.500.000 habitantes.

Odisea, $\mathrm{n}^{\circ}$ 7, ISSN $1578-3820,2006,193-202$ 
En 1759 los fuertes de Niagara, Carillon y Saint-Frédéric caen en manos de los ingleses. Quebec corre igual suerte al año siguiente. Y con la pérdida de Montreal, la Nouvelle France se rinde. Con la conquista de 1760 los habitantes de la Nouvelle France pasan a depender del nuevo régimen que los ingleses imponen después de ganar la guerra. A partir de esta fecha, la historia de la lengua francesa es la historia de un pueblo conquistado y vencido por la fuerza de las armas. El estado francés, como tal, desaparece de la colonia.

Con el tratado de París de 1763 Francia pierde la Acadie, Terranova, la isla de Cabo Breton y todo el territorio de la izquierda del Mississippi. Los administradores ingleses dan dieciocho meses a los franceses para abandonar la colonia, si no se asimilan. Y cambian su nombre por Province of Quebec. Como describe McNaught, "the future was by no means clear in 1760. Indeed, everything was done, as far as London was concerned, to ensure a standard assimilative pattern across the whole of British North America" (1969: 43).

La Royal Proclamation de 1763, según afirma Conway, se convirtió en un "draconian program of forced assimilation... It imposed English civil and criminal law and customs and the use of English" (1992: 13). La imposición de inglés encuentra una resistencia pasiva en el pueblo québécois. En 1774 los ingleses redactaron unas leyes para los habitantes de Quebec que se conocen con el nombre de Quebec Act. Con palabras de Conway, estas leyes "were a complete reversal of the policies embodied in the Royal Proclamation of 1763" (1992: 16). El Quebec Act, prosigue Conway, "was sufficient to ensure the passive neutrality of the québécois during the American War of Independence". Hay que recordar que en los años siguientes a 1774, los tres millones de habitantes de las trece colonias se rebelan contra Inglaterra y piden a los habitantes de la Province of Quebec que se alien con ellos en la guerra contra aquéllos como medio de obtener su independencia. Ésta llega el 4 de julio de 1776. Y Francia, como era de esperar, reconoce inmediatamente al nuevo país: los Estados Unidos de América. Inglaterra tarda unos años. Lo haría en 1783. Los Loyalists prefieren seguir leales a Inglaterra y abandonan los Estados unidos. Unos emigran a Inglaterra, otros a las provincias marítimas y un grupo numeroso a Quebec. Según Conway, "a large group of about seven thousand arrived in Quebec and provided that colony with its first British population of any great significance" (1992: 18). McNaught nos dice que "about 40,000 Loyalists found their way to Nova Scotia and Quebec bringing with them one of the strongest determinants in Canadian history" (1969: 57).

La creciente población inglesa ya no se siente feliz con el Quebec Act de 1774, pues considera que se han dado demasiadas concesiones a las leyes y a la lengua de los québécois. Los ingleses, señala Conway, "wanted English to be the language of daily life, business and politics" (1992: 19). Con esta nueva situación se precisa otra constitución para lograr la reconciliación entre los dos pueblos. Y se consigue con el Constitucional Act de 1791, que para Conway fue una enmienda del Quebec Act (1992: 20). La Province of Quebec se convierte en Upper Canada (inglesa) y Lower Canada (francesa). La línea divisoria al oeste de Montreal incluía una pequeña pero fuerte minoría inglesa. En opinión de Conway, Lower Canada retuvo "the conforts granted to the Quebecois by the Quebec Act" (1992: 20). Los Loyalists exigen un distrito separado con leyes inglesas. Y lo obtienen inmediatamente de Inglaterra. McNaught comenta que estos Loyalists que "streamed into Upper Canada gave hope of balancing the French-speaking population" (1969: 62). Aparecie- 
ron, pues, dos Canadás.

En las elecciones de 1792 en Lower Canada se eligen 35 diputados de lengua francesa y 15 de lengua inglesa. Esto, según Bergeron, fue "une disproportion incroyable quand on sait que les Anglais ne formaient que le quinzième de la population... La langue officielle sera l'anglais. Le français sera admis come langue de traduction" (1971: 68). Después de las elecciones de 1807 se precisa "angliciser" Lower Canada por medio de la inmigración americana y con la unión de Lower y Upper Canada. Los americanos, por su parte, atacan Upper Canada en 1812 y declaran la guerra a Inglaterra. Pero los habitantes de Lower Canada temen tanto al expansionismo americano como a la dominación inglesa. La ocasión era muy propicia para formar aliados. Será en 1818 cuando Inglaterra y América fijen sus fronteras en el paralelo 49.

Después de esta guerra la población de Upper Canada se eleva a 125.000 habitantes. La población de Lower Canada cuenta con 420.000 habitantes de los cuales 80.000 son de habla inglesa (me refiero a la población blanca). Por tanto, los ingleses se encontrarán en minoría en Lower Canada. La única solución que se ve es la unión de las dos Canadás, pues surgen conflictos. Y con las rebeliones de 1837-38 la situación se agrava.

Las partes parecen irreconciliables. El Parlamento británico actúa con contundencia, suspende la constitución de Lower Canada en 1838 y nombra a Lord Durham gobernador general para valorar así las causas de la rebelión. Entre esta fecha y 1910, medio millón de habitantes de Lower Canada se van a los Estados Unidos porque allí ven más futuro que en Quebec. En junio de 1839 Durham presenta su informe, calificado por Conway de "antiQuébécois document that once again reflected the English determination to extinguish the French Fact" (1992: 31). En el informe, "the English language would prevail as the language of government and business" (31). Durham encuentra "two nations warring in the bosom of a single state". Ve el problema, pues, como una lucha entre dos razas. Recomienda la unión como solución al "French-Canadian problem" y la asimilación. También aconseja la inmigración de ingleses de las islas y de los Estados Unidos.

En 1840 se aprueba el Act of Union y se niega el estatus oficial del francés como lengua de debate en la Asamblea, compuesta por 42 miembros de Upper Canada y 42 de Lower Canada. El inglés es la única lengua oficial. Conway afirma que el "Act of Union pleased no one completely, but neither did it offend anyone completely" (1992: 32).

Con la aprobación del Act of Union se crea un Canadá unido. La minoría inglesa ya tiene mayoría. Y la Asamblea ahora se llama Parlamento. La idea de una Confederación empieza a gestarse. Las alternativas posibles son una Confederación o una anexión a los Estados Unidos. Pero a los americanos se les ve como "warlike people". La Confederación significaría una expansión hacia el oeste y una división de Canadá en dos provincias: Ontario y Quebec. Lord Monk en 1865 defiende la Confederación así: "With the public men of British North America it now rests to decide whether the vast tract of country which they inhabit shall be consolidated into a State, combining within its area all the elements of national greatness..." (Waite 1963: iii). Ya en los debates sobre la Confederación se decía que "if the two nationalities were to go agonistic ways, it would leave an important group of English in Canada East under French-Canadian control” (Waite 1963: v).

El motivo principal de la Confederación fue la supervivencia. Se creía que sin una Confederación Canadá sería engullida por la República Americana. Así, según The

Odisea, $n^{\circ} 7$, ISSN 1578-3820, 2006, 193-202 
Constitution Act de 1867, se crea el 29 de marzo "One Dominion under the name of Canada". El artículo 5 dice: "Canada shall be divided into four Provinces, named Ontario, Quebec, Nova Scotia, and New Brunswick". En el artículo 133 se lee que "either the English or the French Language may be used by any Person in the Debates of the Houses of the Parliament of Canada and of the Houses of the Legislature of Quebec... The Acts of the Parliament of Canada and of the Legislature of Quebec shall be printed and published in both those languages".

Más tarde otras provincias negocian la adhesión a la Confederación. Manitoba lo hace en 1870, dando al francés y al inglés el estatus de lenguas oficiales y garantizando dos sistemas escolares. La mitad de la población es francesa. Pero los conflictos no tardan en llegar. En 1885 surge The North West Rebellion y Riel -héroe francés mestizo- es ahorcado el 15 de noviembre de ese mismo año. Manitoba declara que el francés ya no será lengua oficial.

Janet Morchain y Mason Wade opinan que los nacionalistas anglófonos siempre han querido un Canadá monolingüe, buscando hacer del inglés la lengua oficial y obligatoria (1984: 6). Nos ofrecen un catálogo de fechas importantes, compuesto por Abbé Lionel Groulux, en donde se prohíbe el uso del francés. Veámoslo:

1864. Nova Scotia: Se prohíben las escuelas francesas a los Acadiens católicos de habla francesa.

1871. New Brunswick: Se cierran las escuelas francesas católicas y se prohíbe la enseñanza del francés (y en francés) en las escuelas públicas.

1877. Prince Edward Island: Se prohíben las escuelas católicas y francesas.

1890. Manitoba: Se prohíben las escuelas católicas y la enseñanza del francés (y en francés) en las enseñanzas medias.

1892. Northwest Territories (incluyendo lo que es ahora Alberta y Saskatchewan): Se prohíbe la enseñanza del francés en las escuelas públicas y en las católicas.

1905. Alberta and Saskatchewan: Se confirman las disposiciones reglamentarias (Northwest Territories).

1812. Keewatin: Se suprimen las escuelas católicas y se prohíbe la enseñanza del francés.

1812. Ontario: Con la normativa Número 17, se prohíbe el francés en Ontario.

1916. Manitoba: Se prohíbe la enseñanza del francés en todos los niveles.

1930. Saskatchewan: Se prohíbe la enseñanza del francés incluso fuera de las horas de clase.

En 1960 se inicia en Quebec una nueva era con la Quiet Revolution o la Révolution Tranquille. Al llegar al poder Jean Lesage se acelera la transformación del pueblo québécois. Se intenta que el francés sea la lengua de uso en el trabajo y en la vida diaria. Se acuña el eslogan Maîtres chez nous. Se reconoce que, según señala Conway, "for almost a hundred years the two solitudes of Canada had made speeches to each other that neither understood" (1992: 62).

En 1963 el gobierno de Pearson establece la "Royal Commission on Bilingualism and Biculturalism (The B\&B Commission)", y en el informe de 1965 se subraya el hecho de que Canadá se encuentra en "the greatest crisis in its history". Se impone, pues, crear "an equal partnership between the two founding races" (Conway 1992: 63). René Lévesque 
predice la independencia de Quebec en los próximos cinco años. Y el general Charles de Gaulle no ayuda a la posibilidad de un "partnership" con su famosa frase "Vive le Québec Livre!". Desde el gobierno central se lucha contra la separación de Quebec estableciendo programas de bilingüismo. El gobierno de Trudeau introduce en 1969 el Oficial Language Act, que garantiza el estatus paritario del francés y el inglés en todas las instituciones federales. Trudeau, defensor del federalismo, cree necesario seguir una política agresiva de multiculturalismo y bilingüismo para reducir la polarización existente entre las dos lenguas. Sin embargo, Conway afirma que el "federal bilingualism and French power in Ottawa... did nothing to relieve the language tensions in Quebec" (1992: 93). La Quiet Revolution hay que entenderla, con palabras de McNaught, como una revolución "not only against corruption and archaism within Quebec but also against both American and English-speaking Canadian economic and cultural domination" (1969: 298). La Révolution Tranquille tuvo un final dramático con la crisis de octubre de 1970 y los atentados terroristas del F.L.Q. (el Frente de Liberación de Quebec). El horizonte independentista se alejó momentáneamente tras esta aparición de brotes violentos en una sociedad refractaria a toda forma de demostración de fuerza.

Con la ascensión al poder del Partido Québécois (PQ) en 1976, se produce el shock inglés y la esperanza independentista de Quebec. El pueblo québécois había ido ganando terreno desde la Révolution Tranquille. Conway señala que el francés "was gradually becoming the dominant language in Quebec" (1992: 96). En 1978 el PQ introduce La Charte de la langue française. En la Bill 101 o Loi 101, que completaba los trabajos iniciados por el gobierno de Bourassa en 1974 en el Oficial Language Act, el francés, que ya era lengua oficial en Quebec, sale más fortalecido. Para vivir en Quebec desde ahora se necesita saber hablar francés. En el preámbulo de La Charte se lee: "Langue distinctive d'un peuple majoritairement francophone, la langue française permet au peuple québécois d'exprimer son identité". También promete una apertura a las minorías étnicas: "L'Assemblée nacional entend poursuivre cet objective dans un climat de justice et d'ouverture à l'égard des minorités ethniques, dont elle reconnaît l'apport précieux au dévelopment du Québec". En el primer año del PQ en el poder el gobierno provincial lanza el Projet de Société y se manifiesta claramente que en Quebec no hay espacio para el bilingüismo: "Il ne sera donc plus question d'un Québec bilingüe" -leemos en el primer párrafo de dicho Proyecto.

Para los americanos la Loi 101 no supone ningún problema. Sus intereses económicos no están en juego. Pero ante las múltiples presiones que la Loi 101 produce, el gobierno provincial presenta el proyecto de Loi 57 para modificar así la Charte de la langue française. El preámbulo de la Loi 57 reconoce "les institutions de la communauté québécoise d'expression anglaise".

Después de la repatriación de la Constitución canadiense, en 1982, el Canadian Charter of Rights and Freedoms del Constitution Act de 1982, dice en su artículo 16 (1): "English and French are the official languages of Canada and have equality d privileges as to their use in all institutions of the Parliament and government of Canada." Y el artículo 23 (1) señala que los ciudadanos de Canadá

(a) whose first language learned and still understood is that of the English or French linguistic minority population of the province in which they reside, or

Odisea, $\mathrm{n}^{\circ}$ 7, ISSN $1578-3820,2006,193-202$ 
(b) who have received their primary school instruction in Canada in English or French and reside in a province where the language of the English or French linguistic minority population of the province, have the right to have their children receive primary and secondary school instruction in that language in that province.

Quebec no ha firmado estas Leyes Constitucionales de 1982. Estas se adoptaron sin su consentimiento. Por ello, con el fin de establecer nuevos lazos de convivencia y llegar a una reconciliación constitucional con la provincia de Quebec, se inician las conversaciones en el Lago Meech en 1987. Allí, Quebec exige cinco condiciones mínimas en donde se incluye el reconocimiento de Quebec como una "sociedad distinta". Se espera que el Meech Lake Accord satisfaga las objeciones de Quebec a las Leyes Constitucionales de 1982. Unos creen que el acuerdo va a debilitar al sistema federal de Canadá y otros opinan que resolverá la cuestión francesa. El artículo 2 del acuerdo constitucional revisado, de 3 de junio de 1987, reconoce la existencia de "canadiens d'expression française" y de "canadiens d'expression anglaise" concentrados en Quebec. Esto constituye "une caractéristique fundamental du Canada" (Plourde 1988: 112).

A pesar del fracaso del acuerdo, la anterior característica sigue siendo fundamental. Trudeau, que influyó decisivamente en el fracaso del acuerdo del Lago Meech, propone como única alternativa un federalismo bilingüe. Ahora parece que las dos soledades se hallan más alejadas aún de la deseada reconciliación. Ambas caminan por el monolingüismo como única alternativa viable. David Milne cita una tabla de reacciones suscitadas por el acuerdo del Lago Meech (1991: 208). Hay defensores y críticos y cada grupo ofrece sus razones. Para los defensores, el acuerdo proporcionaba entre otros elementos:

- Unidad nacional.

- Reconocimiento de la realidad sociológica de Quebec.

- Reconocimiento de una sociedad distinta.

- Respeto al espíritu del bilingüismo.

- Se asegura la paz y la cooperación intergubernamental.

- Se da a Quebec derecho a seleccionar a los inmigrantes para promocionar su carácter de sociedad distinta, garantizándose así un peso demográfico en la federación.

- Los anglófonos quedan incluidos en la sociedad distinta.

Los críticos (también cito sólo algunas razones), mantenían que:

- Quebec ya estaba legalmente en la Constitución. No fue el pueblo sino el gobierno separatista el que rechazó los cambios de 1982.

- Quebec ya disfrutaba de poderes suficientes para garantizar su seguridad.

- Las instituciones federales quedarían bajo el "control remoto" de los gobiernos provinciales. 
- El nuevo acuerdo no favorecía la unidad nacional, particularmente con los aborígenes. Canadá se convertiría en una mera "comunidad de comunidades".

- Atacaba al bilingüismo.

- Promovía la dualidad linguística de las dos comunidades.

- Discriminaba a las minorías no francófonas.

- Fomentaba el patriotismo provincial antes que el nacional.

Los criterios del Meech Lake Accord rechazaron este acuerdo por su convencimiento de que el mismo significaba un "backdoor to separatism". Trudeau lo calificó como un "fase track towards sovereignty association".

En las elecciones nacionales del 25 de octubre de 1993 se produce "un terremoto político", siendo así como la revista The Economist $(30-5,11,93)$ describió el acontecimiento: El Liberal Party gana 177 escaños, el Bloc Québécois 54, el Reform Party 52, el New Democratic Party 9, el Progressive Conservative 2 y el Independent 1. Las viejas campanas comienzan a sonar. Se precisa reparar el sistema federal. Quebec acelera la marcha y ya se habla de la separación en el espacio de un año, después de las elecciones provinciales del próximo mes de septiembre (1994). Los québécois negociarán la separación si el PQ, bajo la dirección de Jacques Parizeau, gana las elecciones.

Los grandes bancos de Canadá -siempre en la vanguardia- empiezan a reanudar su expansión en el extranjero. Por citar un caso, el Banco de Nueva Escocia compra Inverlat (un grupo mexicano). Otros bancos se dirigen hacia países iberoamericanos y hacia Asia. Compañías como Varita (la antigua Massey-Ferguson) traslada su oficina de Toronto a Buffalo. El comercio en Canadá va siguiendo la ruta norte-sur con una expansión por debajo del paralelo 49. La ruta este-oeste está casi paralizada. Se acusa a Canadá de exigir medidas fuertes contra la contaminación y que las multinacionales paguen sus impuestos. Pero éste es el gran problema. Canadá es un país que depende económicamente de los Estados Unidos. El país está en manos de los americanos (Véase The Betrayal of Canada o "The American TNC in Canada"). Lo importante, pues, no es la independencia de Quebec sino la independencia de Canadá.

La cuestión separatista de Quebec suscita al menos dos posibles respuestas, una emocional y otra racional. Vayamos con la emocional. Se necesita un Quebec unido al resto de Canadá porque como dice el profesor Russell de la Universidad de Toronto, "Canada is a great place" (Young 1991: 95). Sin embargo, hay que condenar el imperialismo del pueblo inglés sobre el pueblo francés a lo largo de la historia. Los canadienses ingleses ni han podido exterminar la lengua de los québécois ni tampoco su cultura. La lengua sigue allí, aunque, como señala Marcel Rioux, se encuentra en un "pitiable state: poverty of vocabulary, anglicisms, syntactic and semantic contaminations and a slackening of articulation in pronunciation. These are the blemishes one usually finds in the speech of French Canadians" (1969: 88).

Todos nos debemos sentir orgullosos de la lengua de los québécois. Es más, los ingleses de Quebec mostrarían sabiduría si participaran activamente de la lengua y la cultura francófona. Éste es un distintivo especial de Canadá: el bilingüismo. Si los québécois son bilingües, son auténticos ciudadanos de un país soberano, con una riqueza linguística que

Odisea, $\mathrm{n}^{\circ}$ 7, ISSN 1578-3820, 2006, 193-202 
otros países desearían. Si los canadienses ingleses sólo hablan inglés, se acercan más a una ciudadanía "manqué". Les falta algo. Es cierto que los canadienses ingleses cuentan con numerosas razones históricas, geográficas y sociológicas para no aprender francés. Pero es precisamente esto lo que les priva de una ciudadanía plenamente participativa.

Vayamos ahora con una respuesta racional. Parece un tanto absurdo hablar de Quebec como una sociedad distinta. Por supuesto que el canadiense francés es diferente al canadiense inglés. Estos dos pueblos son distintos por su cultura y por su lengua. El anglófono necesita saber que la francofonía es una realidad histórica y social de su país. El francófono pide, con justicia, sus derechos lingüísticos y culturales. Pero ambos pueblos necesitan trabajar juntos para reconocer los derechos -no menos justos- del pueblo autóctono, que ha sido olvidado a lo largo de la historia. El cuarto pueblo, los inmigrantes, vino a Canadá a buscar una vida digan, paz y libertad. Y todo esto encontró. Este pueblo ha ayudado notablemente a la construcción del país.

En los tiempos en que vivimos sabemos mucho de desintegración de imperios y desmembramiento de naciones. Las consecuencias son de todos bien conocidas. La separación de Quebec no acabaría en una balcanización del país, como observa Mel Hurtig (1992: 277). Simplemente Quebec acabaría como otro estado más de los Estados Unidos. Y esto sería una negación de la tesis que los canadienses han mantenido a lo largo de su historia. A los Estados Unidos por su parte, no les interesa conquistar un estado que ya controlan. Northrop Frye lo expresó muy bien en una conferencia en la Universidad de Toronto (23 de enero 1999), "Why go to the trouble of annexing a country that is so easy to exploit without taking any responsability for it" (Hurtig 1992: 100).

Un Quebec independiente quedaría aun más en las manos de las multinacionales. Y ya lo está. La separación sería muy costosa económicamente. El coste moral también sería muy elevado. Pero claro, el mundo continuaría. David Milne (1991) nos recuerda -citando a Tucídides- que "ningún estado, ni siquiera la antigua Atenas, es eterno". Canadá puede que tampoco sea eterno.

Los derechos legítimos del pueblo québécois están más seguros en un Canadá unido. El pueblo inglés está obligado a pagar estos derechos, como deuda contraída a lo largo de los años. Los québécois no van a vivir mejor si se separan. Los dirigentes nacionalistas saldrán ganando, pero a costa del pueblo que será -como siempre- el que pagará.

Parece evidente que la solución a la cuestión francesa se resolvería con una actitud reconciliadora de reconocimiento y respeto mutuo entre estos dos grandes pueblos. Sentarse a una mesa de negociaciones con los representantes de los demás pueblos que forman Canadá, para seguir trabajando con vistas a un federalismo más integrador y más participativo, dentro de un marco constitucional, quizá sería un primer paso para mantener un Canadá unido. Aunar todos los esfuerzos, en hermandad, comprensión y colaboración, para trabajar por un Canadá más independiente económicamente de los Estados Unidos, sería un camino más seguro. En todo caso, evitaría el inmenso coste económico y psicológico que el proceso separatista haría caer sobre la mayor parte de la población canadiense, ya sea ésta de origen autóctono, inglés, francés o perteneciente a la inmigración más reciente. 


\section{REFERENCIAS BIBLIOGRÁFICAS}

Bergeon, L. 1971. Petit Manuel d'histoire du Québec. Toronto: Éditions Québécoises.

Conway, J. F. 1992. Debts to Pay. Toronto: James Lorimer \& Company Ltd.

DiETz, B. 1995. Antología de la poesía anglocanadiense contemporánea. Edición bilingüe. Barcelona: Los libros de la frontera.

Gran, G. 1965. Lament for a Nation. Toronto: McClelland \& Stewart Ltd.

Hurtig, M. 1992. A New and Better Canada. Toronto: Stoddart.

McNaught, K. 1969. The Pelican History of Canada. Penguin Books.

Milne, D. 1991. The Canadian Constitution. Toronto: James Lorimer \& Company Ltd.

Morchain, J. \& M. WAdE. 1984. Search for a Nation. XXX. Toronto: Fitzhenry \& Whiteside.

Plourde, M. 1988. La politique linguistique du Québec 1977/1987. Québec: Institut Québécois de Recherche sur la culture.

Rioux, M. 1969. Quebec in Question. Toronto: James Lorimer \& Company Ltd.

The Constitution Acts 1867 to 1982. Department of Justice Canada. Consolidated as of October 1, 1989.

The Economist: October $30^{\text {th }}-$ November $5^{\text {th }}(1993)$; December $4^{\text {th }}-10^{\text {th }}(1993)$; December $18^{\text {th }}-24^{\text {th }}(1993)$; January $15^{\text {th }}-21^{\text {st }}(1994)$; March $14^{\text {th }}-20^{\text {th }}(1998)$.

Torres, J. J. 1992. "The American TNC in Canada". Revista Española de Estudios Canadienses, vol. 1 (3, octubre). 499-506.

Waite, P. B. ed. 1963. The Confederation Debates in the Provinces of Canada/1865. Toronto: MacClelland \& Stewart Ltd.

Woehrling, L. 1992. "A la recherché d'une nouvelle entente constitutionnelle entre le Canada et Québec”. Revista Española de Estudios Canadienses, vol. 1 (3 octubre). 405-431.

Young, R., ed. 1991. Confederation in Crisis. Toronto: Lorimer \& Company Ltd. 